\title{
BOX-BEHNKEN DESIGN FOR PROCESS PARAMETERS OPTIMALIZATION OF BAMBOO-BASED COMPOSITE PANEL MANUFACTURING
}

\author{
Quan Li, Renyuan Liu, Xiaogian Chen \\ Kaili University \\ P. R. CHINA \\ Hui $\operatorname{Lin}^{1,2}$ \\ 1Ningde Normal University \\ ${ }^{2}$ Fujian Provincial Key Laboratory of Featured Materials in Biochemical \\ INDUSTRY \\ P. R. China \\ (Received March 2020)
}

\begin{abstract}
High performance bamboo-based composite panel taking bamboo mats, bamboo curtains and poplar veneers are used as raw material, is manufactured from the each layers slab was crisscrossed, impregnated with phenolic resin, compressed and cured. The product was optimized by Box-Behnken model design and data analysis. The results show that the best parameter conditions were hot pressing temperature of $140^{\circ} \mathrm{C}$, hot pressing time of $94 \mathrm{~s} \cdot \mathrm{mm}^{-1}$, and hot pressing pressure of $2.5 \mathrm{MPa}$. The model was validated according to the optimal process parameters and the static bending strength (MOR), elastic modulus (MOE), thickness expansion rate of water absorbing, adhesive strength and density are $98.95 \mathrm{MPa}, 8.81 \mathrm{GPa}, 4.7 \%$, $1.25 \mathrm{MPa}, 0.89 \mathrm{~g} \cdot \mathrm{cm}^{-3}$, respectively. The actual value is close to the predicted value, confirming that the obtained model can accurately predict the MOR of the product using the three factors of hot pressing as variables under different conditions.
\end{abstract}

KEYWORDS: Moso bamboo, static bending strength, hot pressing, Box-Behnken design.

\section{INTRODUCTION}

The diminishing wood resource and restrictions imposed on felling in natural forests, particularly in the tropics, have focused world attention on the need to identify a substitute material which should be renewable, environmentally friendly and widely available. Bamboo 
is predominately perceived as a timber substitute. Both bamboo and wood are naturally grown biomass, and both belong to heterogeneous and anisotropic materials. The structure of bamboo is considerably different from that of wood (Bahari and Krause 2016). Compared with wood, bamboo has the characteristics of straight texture, high strength, high toughness and good economic, social and ecological benefits (Guo et al. 2018). Moso bamboo (Phyllostachys edulis) is a large, woody bamboo with the highest ecological, economic, and cultural value of all bamboo types and accounts for $70 \%$ of the total cultivated bamboo worldwide (Song et al. 2016, Zakikhani et al. 2017). Generally, bamboo-based artificial board have better physical and mechanical properties than wood-based artificial board, which have been widely used in construction engineering, furniture manufacturing (Xie et al. 2016, Ugwuishiwu et al. 2018). Bamboo has a great potential development, so it is essential to study bamboo products and pay attention to taking bamboo and small caliber raw bamboo as major materials to produce various bamboo products, which conforms to peoples life ideas to adorn and return to nature (Chow et al. 2019).

Many studies related to bamboo-based composite panel were reported (He et al. 2018). The kinds of bamboo-based panel were various in market, which included reconstituted bamboo engineering timber, laminated bamboo veneer lumber, bamboo flooring, bamboo flakeboard and laminated bamboo strip lumber. The composite structure and raw materials of bamboobased composite panel is known to determine the physical and mechanical properties (Liu et al. 2017, Javadian et al. 2020). Using bamboo-based construction materials has been identified as a potential way of reducing pressure on resources and on the environment (Escamilla et al. 2014). Huang et al. (2017) investigated bamboo hygrothermal properties and the impact of bamboobased panel (BBP) process. Comparison between five $\mathrm{BBP}$ and flattened raw bamboo show that the $\mathrm{BBP}$ process improves homogeneity and broadens the material properties spectrum. Use of bamboo-based panels is seen increasingly high and the use bamboo as an alternative can be seen in productions such as furniture, automotive and other related productions (Guan et al. 2018). The utilization of bamboo fibres as reinforcement in composite materials has increased tremendously and has undergone high-tech revolution in recent years as a response to the increasing demand for developing biodegradable, sustainable, and recyclable materials (Okubo et al. 2004, Khalil et al. 2012). Holmes et al. (2009) examines the mechanical properties of a novel bamboo-poplar epoxy laminate which is being developed for wind turbine blades. Bamboo has many engineering and environmental attributes that make it an attractive material for utilization in wind turbine blades (Meng et al. 2017). All these studies show that bamboo-based panels are one of prefabrication materials with great potential. The development of high performance bamboo-based composite panel is great significance for protecting the ecological environment and developing high value-added bamboo processing industry. High-performance bamboo-based composite panel is a new structural sheet with excellent mechanical properties and good dimensional stability. The purpose of this study is to improve the mechanical properties of bamboo-based panel, extend their service life, and greatly improve their application quality and comprehensive utilization of bamboo materials, so that this product will eventually replace fine solid wood in structural timber in structural construction.

\section{MATERIAL AND METHODS}

\section{Materials}

6 8 years old moso bamboo (Phyllostachys heterocycla) was used as raw material. Bamboo curtains and bamboo mats were cut and knitted by slitting machine. Thick bamboo curtain was knitted with thick cotton thread, and its width was $10 \sim 20 \mathrm{~mm}$, thickness was $2.0 \sim 2.5 \mathrm{~mm}$. Thin 
bamboo curtain was knitted with fine cotton thread, and its width was $10 \sim 20 \mathrm{~mm}$, thickness was 1.0 1.2 mm. The width of the bamboo mat was $10 \sim 20 \mathrm{~mm}$ and the thickness was $0.5 \sim 0.7 \mathrm{~mm}$. It was mechanically woven. The surface of the bamboo mat was even, non-mildew and tightly woven. After drying, the moisture content of the bamboo curtain and bamboo mat was about $9 \%$. Poplar veneer ( $1.2 \mathrm{~mm}$ thickness, dried to $8 \%$ moisture content) was purchased from the forest products market.

Phenolic resin adhesive, solid content is $55 \%$, viscosity is $5700 \sim 5800 \mathrm{cps}, \mathrm{pH}$ is 6 , free phenol content is $\leq 0.2 \%$, red brown adhesive. Hot pressing equipment: LB-D1.00MN, produced by Qingdao Yahua Company. Universal mechanical testing machine: WDW-100, Jinan Hengsida Instrument Co., Ltd.

\section{Manufacture process of bamboo-based composite panel}

After cutting, the bamboo green, bamboo yellow of moso bamboo were scraped and the bamboo curtains and bamboo mats are woven out. Dry the moisture content of bamboo to $10 \%$. The thick bamboo curtain and bamboo mat were immersed in the adhesive tank with 55\% phenolic resin adhesive for $7 \mathrm{~min}$, so that the sizing amount reached about $9 \%$. After drying the adhesive, the thick bamboo curtain and bamboo mat should be kept in the shade. The bamboo curtain and bamboo mat surface after impregnating phenolic resin adhesive, thick bamboo curtain and poplar veneer without impregnating adhesive, all the materials were combined into a slab.

\section{Technological process}

When forming the blank, the bamboo mat, bamboo curtain, poplar veneer was formed according to the principle of symmetry and odd number layer. Form blanks according to layers crisscross. The plate blank with a thickness of about $18.5 \mathrm{~mm}$ after being assembled was sent to a hot press to be hot pressed to obtain a product with a thickness of $15 \mathrm{~mm}$ and there are 13 floors in total. The structure of the plate blank assembly is a mutually perpendicular structure of a thick curtain and a thin curtain for adjacent bamboo curtains, which had the advantages of both thin curtain plate and thick curtain plate.

\section{Single factor experiment}

Take the three factors of hot pressing temperature, hot pressing time and hot pressing pressure as variables, and use the static bending strength (MOR) as the evaluation index. The single factor test level is shown in Tab. 1.

Tab. 1: Factors and levels in single factor experiment.

\begin{tabular}{|l|c|c|c|}
\hline \multicolumn{1}{|c|}{ Factors } & 1 & 2 & 3 \\
\hline Hot pressing temperature $\left({ }^{\circ} \mathrm{C}\right)$ & 135 & 145 & 155 \\
\hline Hot pressing time $\left(\mathrm{s} \cdot \mathrm{min}^{-1}\right)$ & 80 & 90 & 100 \\
\hline Hot pressing pressure $(\mathrm{MPa})$ & 2.0 & 2.2 & 2.4 \\
\hline
\end{tabular}

\section{Response surface analysis test}

Based on the results of the single factor test, the Box-Behnken design of 17 runs was used to statistically optimize the MOR, and the effects of the hot pressing temperature, hot pressing time and hot pressing pressure on the MOR of the product were considered. $-1,0$ and 1 represent the low, medium and high levels of the independent variables, respectively. The test design factors and levels are shown in Tab. 2. 
Tab. 2: Factors and levels in response surface design.

\begin{tabular}{|l|c|c|c|}
\hline \multirow{2}{*}{\multicolumn{1}{|c|}{ Factors }} & \multicolumn{3}{|c|}{ Level } \\
\cline { 2 - 4 } & -1 & 0 & 1 \\
\hline Hot pressing temperature $\left({ }^{\circ} \mathrm{C}\right)$ & 125 & 135 & 145 \\
\hline Hot pressing time $\left(\mathrm{s} \cdot \mathrm{min}^{-1}\right)$ & 80 & 90 & 100 \\
\hline Hot pressing pressure $(\mathrm{MPa})$ & 2.2 & 2.4 & 2.6 \\
\hline
\end{tabular}

\section{Test method}

According to china national standards (Test methods of evaluating the properties of woodbased panels and surface decorated wood-based panels, GB/T 17657-2013), the elastic modulus (MOE), static bending strength (MOR), thickness expansion rate of water absorbing, bonding strength and density were tested.

\section{RESULTS AND DISCUSSION}

\section{Effect of hot pressing temperature on MOR}

It can be seen from Fig. 1 that the hot pressing temperature has a great influence on the curing speed of the phenol resin adhesive. When the temperature is too low, to ensure that the performance of the panel meets the requirements, sufficient hot pressing time is required (Gao et al. 2018). Increasing the hot pressing temperature is conducive to improving the plasticity of the bamboo material and speeding up the curing of the adhesive, so that the contact between the bamboo mat and the bamboo curtain are closer, thereby improving the strength of the panel (Chang et al. 2020).

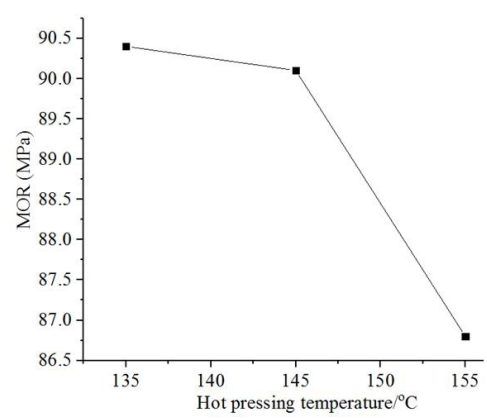

Fig. 1: Mean value of $M O R$ in different hot pressing temperature.

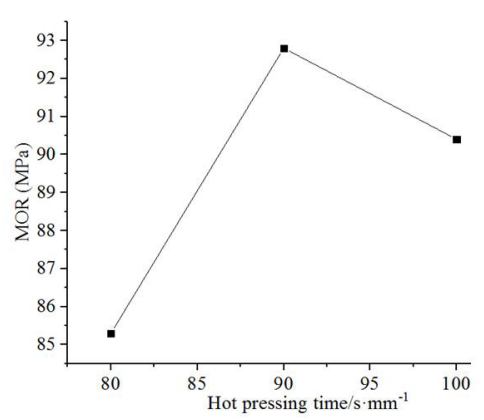

Fig. 2: Mean value of MOR in different hot pressing time.

Within the proper temperature range, the higher the temperature, the faster the phenolic resin adhesive will cure, the longer the hot pressing time, and the better the bonding strength, but too high temperature will cause the phenolic resin to degrade and become brittle. It is verified by experiments that it is more appropriate to control the hot pressing temperature at about $135^{\circ} \mathrm{C}$.

\section{Effect of hot pressing time on MOR}

It can be seen from Fig. 2 that the adhesive is completely cured under the appropriate hot pressing pressure and temperature conditions. It takes a certain time to complete the panel 
bonding, which includes the curing time of the adhesive and the evaporation time of water in the panel. If the moisture content of the slab is too high during hot pressing, it will cause bubbling of the panel. If the hot pressing time is too short, the curing rate of the adhesive is low, so that the bonding strength cannot meet the quality requirements. Holding pressing time is too long, will make the panel and adhesive layer brittle, even carbonization (Wang et al. 2017, Yan and Benhua 2019). In the process of holding pressure, usually the curing rate of the adhesive must reach more than $90 \%$ to ensure the bonding strength of the bamboo-based composite panel. The hot pressing time selected in this test is more suitable at $90 \mathrm{~s} \cdot \mathrm{mm}^{-1}$.

\section{Effect of hot pressing pressure on MOR}

Hot pressing pressure has a positive correlation with panel density and raw material consumption (Fig. 3).

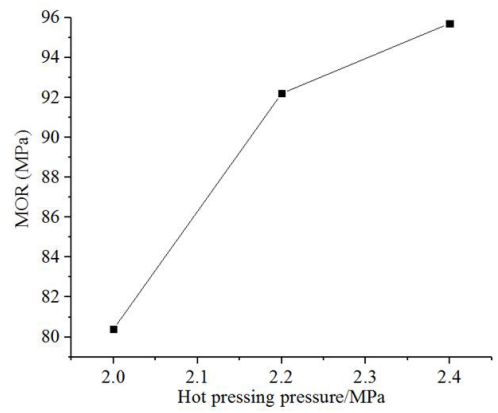

Fig. 3: Mean value of MOR in different hot pressing pressure.

Properly hot pressing pressure is conducive to densification of slabs of bamboo-based composite panel, reducing the gap of the adhesive layer, increasing the cohesion of the molecules of the adhesive, and improving the service life of the mechanical properties of the product. If the pressure is too low, it will lead to lack of adhesive or accumulation of adhesive, which is not conducive to gluing. If the pressure is too high, the density of the plate will increase (Zhang et al. 2019, Zhao et al. 2019). Although the mechanical properties of the panel will increase, it will cause problems such as the consumption of raw materials and the thickness expansion rate of water absorbing, which will increase the production cost. Taking into account various factors, the hot pressing pressure under single-factor test conditions is determined to be $2.4 \mathrm{MPa}$.

\section{Response surface design results}

The hot pressing temperature, hot pressing time, and hot pressing pressure was taken as the influencing factors to discuss the hot pressing process parameters of the high performance bamboo-based composite panel. The experimental design and results are shown in Tab. 3.

Tab. 3: Box-Behnken experiment design and results.

\begin{tabular}{|c|c|c|c|c|}
\hline No. & $\begin{array}{c}\text { Hot press. } \\
\text { temperature } \mathbf{A}\left({ }^{\circ} \mathbf{C}\right)\end{array}$ & $\begin{array}{c}\text { Hot press. time } \\
\mathbf{B}\left(\mathbf{s} \cdot \mathbf{m m}^{-\mathbf{1}}\right)\end{array}$ & $\begin{array}{c}\text { Hot press. pressure } \\
\mathbf{C}(\mathbf{M P a})\end{array}$ & MOR Y (MPa) \\
\hline 1 & 125 & 100 & 2.4 & 88.7 \\
\hline 2 & 135 & 90 & 2.4 & 90.3 \\
\hline 3 & 145 & 90 & 2.6 & 98.4 \\
\hline
\end{tabular}




\begin{tabular}{|c|c|c|c|c|}
\hline 4 & 145 & 90 & 2.2 & 89.3 \\
\hline 5 & 135 & 90 & 2.4 & 98.4 \\
\hline 6 & 145 & 80 & 2.4 & 87.5 \\
\hline 7 & 135 & 90 & 2.4 & 97.1 \\
\hline 8 & 135 & 80 & 2.2 & 82.4 \\
\hline 9 & 125 & 90 & 2.6 & 81.8 \\
\hline 10 & 125 & 80 & 2.4 & 80.4 \\
\hline 11 & 135 & 90 & 2.4 & 94.8 \\
\hline 12 & 135 & 100 & 2.6 & 96.4 \\
\hline 13 & 135 & 100 & 2.2 & 83.5 \\
\hline 14 & 135 & 90 & 2.4 & 99.7 \\
\hline 15 & 145 & 100 & 2.4 & 86.4 \\
\hline 16 & 125 & 90 & 2.2 & 78.58 \\
\hline 17 & 135 & 80 & 2.6 & 79.85 \\
\hline
\end{tabular}

\section{Regression model analysis}

The experimental data (Tab. 3) were fitted with quadratic multiple regression. The MOR of bamboo-based composite panel could be expressed as the following eq. 1 :

$$
Y=96.06+4.02 A+3.11 B+2.83 C-2.35 A B+1.47 A C+3.86 B C-4.41 A^{2}-5.9 B^{2}-4.63 C^{2}
$$

where: $Y$ is the MOR; $A, B, C$ are the coded variables for the hot pressing temperature, hot pressing time, and hot pressing pressure, resp.

Statistical testing of the model was performed by analysis of variance (ANOVA) (Adamu et al. 2019, Gao et al. 2019). Tab. 4 lists the analysis results of variance and regression coefficients. A large $F$-value (4.21) with a small $p$-value (0.0001) indicated that the effect on the respective response variables was significant. The coefficients $A$ and $B^{2}$ were significant $(p<0.05)$, and the coefficient of $B, C, A B, B C, C^{2}, B^{2}$ and $C^{2}$ were insignificant ( $p>0.05$ ). In addition, the validation of model was measured by lack of fit testing. The $p$-value of the lack of fit was 0.2718 , which implied that the model was appropriate for predicting the MOR.

Tab. 4: Variance analysis of regression model.

\begin{tabular}{|c|c|c|c|c|c|}
\hline Source & Sum of squares & $\begin{array}{c}\text { Degree of } \\
\text { freed. of var. }\end{array}$ & Mean square & $\boldsymbol{F}$ value & Prob $>\boldsymbol{F}$ \\
\hline Model & 715.89 & 9 & 79.54 & 4.21 & 0.0355 \\
\hline$A$ & 128.96 & 1 & 128.96 & 6.83 & 0.0347 \\
\hline$B$ & 77.19 & 1 & 77.19 & 4.09 & 0.0828 \\
\hline$C$ & 64.24 & 1 & 64.24 & 3.4 & 0.1075 \\
\hline$A B$ & 22.09 & 1 & 22.09 & 1.17 & 0.3151 \\
\hline$A C$ & 8.64 & 1 & 8.64 & 0.46 & 0.5203 \\
\hline$B C$ & 59.68 & 1 & 59.68 & 3.16 & 0.1186 \\
\hline$A^{2}$ & 82.03 & 1 & 82.03 & 4.35 & 0.0755 \\
\hline$B^{2}$ & 146.38 & 1 & 146.38 & 7.76 & 0.0271 \\
\hline$C^{2}$ & 90.11 & 1 & 90.11 & 4.78 & 0.0651 \\
\hline
\end{tabular}




\begin{tabular}{|c|c|c|c|c|c|}
\hline Residual & 132.1 & 7 & 18.87 & & \\
\hline Lack of Fit & 77.53 & 3 & 25.84 & 1.89 & 0.2718 \\
\hline Pure Error & 54.57 & 4 & 13.64 & & \\
\hline Cor toal & 847.99 & 16 & & & \\
\hline$R^{2}$ & 0.8442 & & & & \\
\hline Adj $R^{2}$ & 0.8624 & & & & \\
\hline Pred $R^{2}$ & 0.8358 & & & & \\
\hline C.V.\% & 4.88 & & & & \\
\hline
\end{tabular}

The determination coefficient $\left(R^{2}\right)$ is defined as the regression of sum of squares proportion to the total sum of squares which demonstrates the adequacy of a obtained model. The $R^{2}(0.8442)$ of this model was close to 1 , which indicated that almost all of the variations found on the MOR could be explained by the model. The adjusted determination coefficient (Adj R 2 ) and predicted determination coefficient $\left(\operatorname{Pred} R^{2}\right.$ ) of also illustrate whether the model adequately fits the data. The Adj $R^{2}(0.8624)$ and Pred $R^{2}$ (0.8358), which were also close to 1 , indicating the observed experimental data have a high degree of correlation with the predicted values. Furthermore, a low value of the coefficient of variation $(C . V .=4.88 \%)$ also indicated a high degree of precision and a good deal of reliability of the experimental data. All these above results revealed that the obtained model had adequately represented the real relationship between the response (MOR) and independent variables (hot pressing temperature, hot pressing time, and hot pressing pressure). In addition, three-dimensional (3D) surface plots and two-dimension (2D) contour plots demonstrate relationship between the hot pressing and the MOR of the product.

\section{Response surface interaction analysis}

It can be seen from Figs. 4 to 5 that MOR first increases with the increase of the hot pressing temperature and hot pressing time. It decreases with the increase of hot pressing pressure, when the hot pressing temperature and hot pressing time reach $139.5^{\circ} \mathrm{C}$ and $92.5 \mathrm{~s} \cdot \mathrm{mm}^{-1}$, respectively.

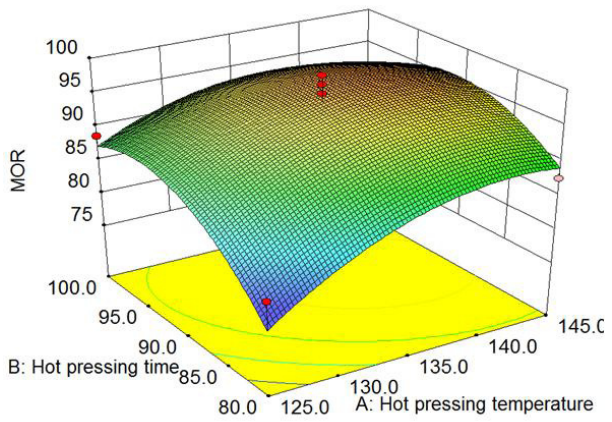

Fig. 4: Response surface of the effects of temperature and time.

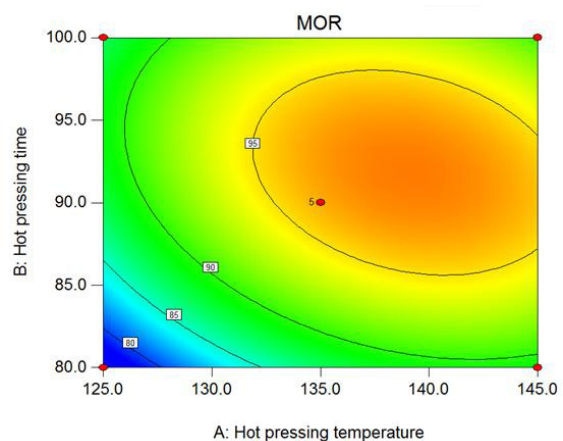

Fig. 5: Contours of the effects of temperature and time.

It can be seen from Figs. 6 to 7 that the response surface diagrams of the effects of hot pressing temperature and hot pressing pressure on the MOR of the product under the condition of $90 \mathrm{~s} \cdot \mathrm{mm}^{-1}$ hot pressing time. 


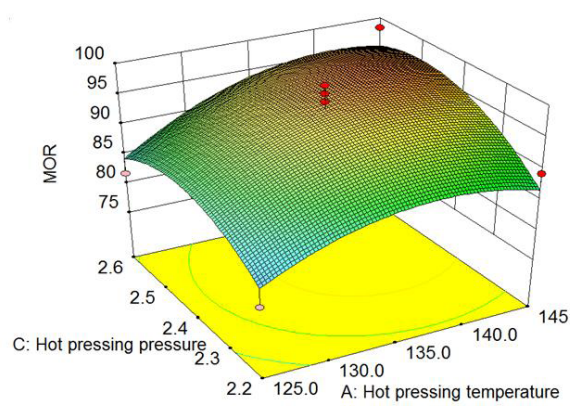

Fig. 6: Response surface of the effects of temperature and pressure.

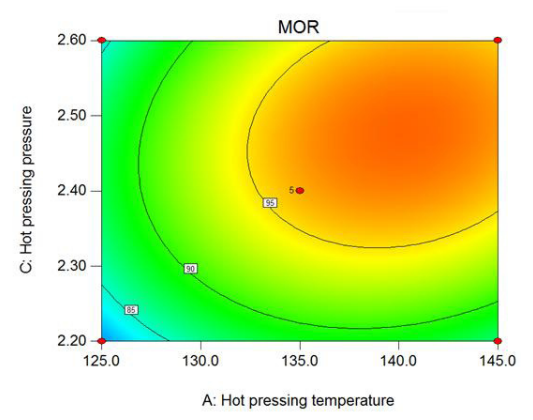

Fig. 7: Contours of the effects of temperature and pressure.

As can be seen from Figs. 8 and 9, the effect of hot pressing pressure and time on the MOR. With the increase of hot pressing pressure and time, MOR increases, but when the pressure exceeds $2.5 \mathrm{MPa}$ and the time exceeds $94.3 \mathrm{~s} \cdot \mathrm{mm}^{-1}$, the MOR decreases. Compared with other studies on the optimization of wood-based panel, the response surface method reduces the number of experimental tests and evaluates the interaction between multiple parameters. This efficient design can be more effective arrange and explain hot pressing experiments (Guan et al. 2018, Deng et al. 2020).
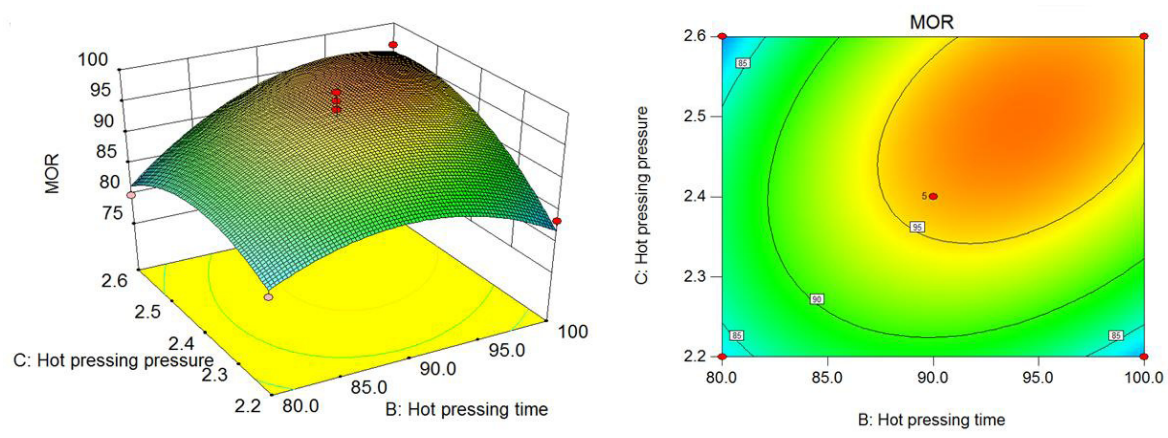

Fig. 8: Response surface of the effects of pressure Fig. 9: Contours of the effects of pressure and time. and time.

\section{Verification of optimal conditions}

From the model, the optimum parameters of the optimal hot pressing process for bamboobased composite panel are determined as the hot pressing temperature $(\mathrm{A})$ of $139.5^{\circ} \mathrm{C}$, hot pressing pressure (B) of $2.50 \mathrm{MPa}$, and hot pressing time (C) of $93.45 \mathrm{~s} \cdot \mathrm{mm}^{-1}$. Considering the operability in the actual application, the conditions were modified as follows: temperature (A) of $140^{\circ} \mathrm{C}$, pressure (B) of $2.5 \mathrm{MPa}$, and time $(\mathrm{C})$ of $94 \mathrm{~s} \cdot \mathrm{mm}^{-1}$. Under the optimal extraction conditions, the MOR was $98.95 \mathrm{MPa}$, the $\mathrm{MOE}$ is $8.81 \mathrm{GPa}$, the thickness expansion rate of water absorbing is $4.7 \%$, the bonding strength is $1.25 \mathrm{MPa}$, and the density is $0.89 \mathrm{~g} \cdot \mathrm{cm}^{-3}$. MOR was close to the predicted value of $98.24 \mathrm{MPa}$. The good correlation between the experimental data and predicted values confirmed that the obtained model could accurately predict the MOR. Those above results 
proved that Box-Behnken design is an effective method for optimization of process parameters in high performance bamboo-based composite panel manufacturing. Due to the use of poplar veneer on the surface of the bamboo-based composite panel, the surface is smoother than the bamboo plywood template. In addition, the bamboo mat and bamboo curtain are used inside the panel. Its MOE, MOR, and thickness expansion rate of water absorbing, bonding strength and density all exceed the requirements of China national standards JG/T 156-2004.

\section{CONCLUSIONS}

The high-performance bamboo-based composite panel manufacturing by using innovative technology has good mechanical properties. The experimental results show that the response surface method is effective in optimizing the hot pressing process of high performance bamboobased composite panel manufacturing. Box-Behnken experimental design established a quadratic multinomial mathematical model of the influence of hot pressing on product MOR, and used statistical methods to test the significance of the model, optimize the level of internal factors, and find the best value. The experimental results show that the actual value of product MOR is close to the theoretical predicted value

\section{ACKNOWLEDGEMENTS}

This research was supported by Open topic of key laboratory of green energy and environment catalysis (FJ-GEEC202005), open topic of fujian provincial key laboratory of featured materials in biochemical Industry (FJKL_FBCM202004), Scientific Research Project for young and middle-aged teachers of Ningde Normal University (2017Q103) and Youth science and technology talent development project of Education department in Guizhou Province (2018KY365).

\section{REFERENCES}

1. Adamu, M., Rahman, M.R., Hamdan, S., 2019: Formulation optimization and characterization of bamboo/polyvinyl alcohol/clay nanocomposite by response surface methodology. Composites Part B: Engineering 176: 107297.

2. Bahari, S.A., Krause, A., 2016: Utilizing Malaysian bamboo for use in thermoplastic composites. Journal of Cleaner Production 110: 16-24.

3. Chang, F., Liu, Y., Zhang, B., Fu, W., Jiang, P., Zhou, J., 2020: Factors affecting the temperature increasing rate in arc-shaped bamboo pieces during high-frequency heating. BioResources 15(2): 2656-2667.

4. Chow, A., Ramage, M.H., Shah, D.U., 2019: Optimising ply orientation in structural laminated bamboo. Construction and Building Materials 212: 541-548.

5. Deng, J., Wei, X., Zhou, H., Wang, G., Zhang, S, 2020: Inspiration from table tennis racket: Preparation of rubber-wood-bamboo laminated composite (RWBLC) and its response characteristics to cyclic perpendicular compressive load. Composite Structures 241: 112-135. 
6. Escamilla, E.Z., Habert, G., 2014: Environmental impacts of bamboo-based construction materials representing global production diversity. Journal of Cleaner Production 69: 117-127.

7. Gao, L., Guo, W., Luo, S., 2018: Investigation of changes in compressed moso bamboo (Phyllostachys pubescens) after hot-press molding. Journal of wood science 64(5): 557-565.

8. Gao, L., Luo, S., Guo, W., 2019: Optimization of performance of bamboo mat corrugated sheets using response surface methodology. Wood and Fiber Science 51(3): 1-12.

9. Guan, X., Yin, H., Liu, X., Wu, Q. Gong, M., 2018: Development of lightweight overlaid laminated bamboo lumber for structural uses. Construction and Building Materials 188: 722-728.

10. Guo, Y., Zhu, S., Chen, Y., Shengquanliu, Q. 2018: Contrastive analysis of screw withdrawal resistance between bamboo oriented strandboard and conventional particleboard. Wood Research 63(6): 1071-1080.

11. He, S., Xu, J., Wu, Z.X., Yu, H., Chen, Y.H., Song, J. G., 2018: Effect of bamboo bundle knitting on enhancing properties of bamboo scrimber. European Journal of Wood and Wood Products 76(3): 1071-1078.

12. Holmes, J.W., Brøndsted, P., Sørensen, B.F., Jiang, Z., Sun, Z., Chen, X., 2009: Development of a bamboo-based composite as a sustainable green material for wind turbine blades. Wind Engineering 33(2): 197-210.

13. Huang, Z., Sun, Y., Musso, F., 2017: Experimental study on bamboo hygrothermal properties and the impact of bamboo-based panel process. Construction and Building Materials 155: 1112-1125.

14. Javadian, A., Smith, I.F., Hebel, D.E, 2020: Application of Sustainable bamboo-based composite reinforcement in structural-concrete beams: Design and evaluation. Materials 13(3): 696.

15. Khalil, H.A., Bhat, I.U.H., Jawaid, M., Zaidon, A., Hermawan, D., Hadi, Y.S., 2012: Bamboo fibre reinforced biocomposites: A review. Materials \& Design 42: 353-368.

16. Liu, H., Jiang, Z., Sun, Z., Yan, Y., Cai, Z., Zhang, X., 2017: Impact performance of two bamboo-based laminated composites. European Journal of Wood and Wood Products 75(5): 711-718.

17. Meng, J., Sun, D., 2017: Research on vibration suppression of wind turbine blade based on bamboo wall three-layer damping structure. Journal of Vibroengineering 19(1): 87-99.

18. Okubo, K., Fujii, T., Yamamoto, Y., 2004: Development of bamboo-based polymer composites and their mechanical properties. Composites Part A: Applied science and manufacturing 35(3): 377-383.

19. Song, X., Peng, C., Zhou, G., Gu, H., Li, Q. Zhang, C., 2016: Dynamic allocation and transfer of non-structural carbohydrates, a possible mechanism for the explosive growth of Moso bamboo (Phyllostachys heterocycla). Scientific reports 6: 25908.

20. Ugwuishiwu, B.O., Eke, V.N., Echiegu, E.A., Nwakaire, J.N., Nwoke, O.A., Mama, B., Ezeagba, C., 2018: Mechanical properties of tropical bamboo reinforced PVA for fibreboard production. Science and Technology 11(5): 262-268.

21. Wang, B., Li, D.L., Chen, T.Y., Qin, Z.Y., Peng, W.X., Wen, J.L., 2017: Understanding the mechanism of self-bonding of bamboo binderless boards: investigating the structural changes of lignin macromolecule during the molding pressing process. BioResources 12(1): 514-532. 
22. Xie, J., Qi, J., Hu, T., Cornelis, F., Hse, C.Y., Shupe, T.F., 2016: Effect of fabricated density and bamboo species on physical-mechanical properties of bamboo fiber bundle reinforced composites. Journal of materials science 51(16): 7480-7490.

23. Yan, Y., Benhua, F., 2019: Axial compression properties of bamboo/wood composite column constrained with sliced bamboo veneer. Wood Research 64(5): 891-902.

24. Zakikhani, P., Zahari, R., Sultan, M., Majid, D., 2017: Morphological, mechanical, and physical properties of four bamboo species. BioResources 12(2): 2479-2495.

25. Zhang, X., Zhou, Z., Zhu, Y., Dai, J., Yu, Y., Song, P., 2019: High-pressure steam: a facile strategy for the scalable fabrication of flattened bamboo biomass. Industrial crops and products 129: 97-104.

26. Zhao, W., Yang, B., Zhou, J., 2019: Axial compressive creep behaviour of a square steel tube/bamboo plywood composite column with binding bars. Wood Research 64(2): 223-235.

\author{
Quan Li, Renyuan Liu, Xiaogian Chen \\ Kaili University \\ KAILI \\ P. R. CHINA \\ Hui Lini,2* \\ ${ }^{1}$ College of Chemistry and Materials, Ningde Normal University \\ 2Fujian Provincial Key Laboratory of Featured Materials \\ in Biochemical Industry \\ Ningde \\ P. R. China \\ *Corresponding author: linhui@ndnu.edu.cn
}


